\title{
PERANCANGAN APLIKASI SISTEM PENUNJANG KEPUTUSAN MENENTUKAN LOKASI PASAR UNTUK PEDAGANG PADA KANTOR PELAYANAN PASAR KOTA DUMAI MENGUNAKAN METODE SAW
}

\author{
Firmandi $^{1}$, Amat Sofiyan ${ }^{2}$, Ade Saputra ${ }^{3}$, Fitri Pratiwi ${ }^{4}$ \\ ${ }^{1,2,3,4}$ Sekolah Tinggi Manajemen Informatika Dan Komputer ( STMIK ) Dumai \\ Jln. Utama Karya Bukit Batrem Dumai-Riau Kode Pos 28811 \\ E-mail : Firmandi777@gmail.com
}

\begin{abstract}
ABSTRAK
Penelitian ini dilakukan untuk merancang sebuah aplikasi, dimana selama ini masalah yang dihadapi dalam persoalan untuk menentukan lokasi pasar untuk pedagang masih secara manual yaitu dengan cara melakukan penyeleksian bagi calon pedagang. Perancangan aplikasi terdiri dari rancangan output, rancangan input, dan rancangan file, dimana dengan menggunakan logika pemograman diharapkan input, proses dan output yang dihasilkan sesuai yang diharapkan. Manfaat dari penelitian ini yaitu agar dapat mempermudah dalam menentukan lokasi pasar untuk pedagang berdasarkan kriteria-kriteria yang telah ditetapkan oleh kantor pelayanan pasar secara efisien. Dan dalam perancangan aplikasinya, digunakan bahasa pemograman Visual Basic 6.0 dengan database MySql yang bertujuan agar lebih mudah dimengerti oleh pemakai (user).
\end{abstract}

Kata Kunci : Aplikasi, SPK, Lokasi Pasar, SAW, Pedagang

\section{PENDAHULUAN}

Pasar tradisional milik pemerintah merupakan pasar yang dibangun dan dikelola oleh pemerintah, pemerintah daerah, Badan Usaha Milik Negara dan Badan Usaha Milik Daerah dengan tempat usaha berbentuk toko, kios, los dan lapak yang dimiliki dan dikelola oleh pedagang kecil, menengah, swadaya masyarakat atau koperasi , Permasalahan yang terdapat pada setiap pasar tradisonal di Dumai umumnya hampir sama yaitu belum efektifnya penentuan lokasi pasar bagi pedagang, Untuk membantu pihak kantor pelayanan pasar dalam menentukan lokasi pasar bagi pedagang dikota Dumai maka diperlukan sebuah sistem yang mampu menentukan lokasi pasar bagi pedagang berdasarkan kriteria yang sesuai dengan pedagang itu sendiri menggunakan metode SAW

Berdasarkan latar belakang masalah diatas, maka dapat diidentifikasikan masalah-masalah yang sering terjadi adalah sebagai berikut :

1. Saat ini Kantor Pelayanan Pasar Kota Dumai belum memiliki aplikasi sistem penunjang keputusan untuk menentukan lokasi pasar bagi pedagang yang berada dikota Dumai berdasarkan kriteria-kriteria yang dimiliki oleh masing-masing pedagang .

2. Memungkinkan terjadinya redudansi data karena tidak mengunakan DataBase sebagai media penyimpanannya.

3. Membutuhkan waktu yang cukup lama untuk menentukan lokasi pasar berjualan pedagang dikota Dumai.

4. Sulitnya dalam pembuatan laporan hasil penempatan pedagang disalah satu pasar per periode di kota Dumai karena pembuatan laporan masih secara manual.

Agar dalam penelitian ini menjadi lebih terarah serta bertujuan untuk menghindari terjadinya penyimpangan dari tujuan yang akan dicapai maka ruang lingkup penelitian ini meliputi hal berikut ini :

1. Penelitian dilakukan di Kantor Pelayanan Pasar Kota Dumai

2. Bahasa pemograman yang digunakan adalah Visual Basic 6.0

3. Database yang digunakan adalah MySQL Versi 5.0 
I N F O R M A I K A

Jurnal Informatika, Manajemen dan Komputer, Vol. 8 No. 2 , Desember 2016

eISSN : 2580-3042

pISSN : 1979-0694

Dan adapun tujuan dari penelitan imi adalah sebagai berikut :

1 Untuk menganalisa dan mengetahui tentang penentuan lokasi pasar bagi pedagang menggunakan metode SAW.

2 Mengimplementasikan ilmu yang telah diperoleh selama bangku perkuliahan baik teori mapun praktek.

3 Membuat sebuah perancangan aplikasi sistem penunjang keputusan untuk membantu pihak Kantor Pelayanan Pasar Kota Dumai dalam proses menentukan lokasi pasar bagi pedagang dikota Dumai Mengunakan metode SAW.

\section{a. Pengertian Pasar}

Pasar adalah salah satu dari berbagai sistem, institusi, prosedur, hubungan orang-orang dengan imbalan uang. Barang dan jasa yang dijual menggunakan alat pembayaran yang sah seperti uang. ${ }^{1}$

\section{b. Pengertia Pedagang}

Pedagang adalah orang yang melakukan perdagangan, memperjualbelikan barang yang tidak diproduksi sendiri, untuk memperoleh suatu keuntungan Pedagang dapat dikategorikan menjadi:

1. Pedagang Grosir, beroperasi dalam rantai distribusi antara produsen dan pedagang eceran.

2. Pedagang Eceran, disebut juga pengecer, menjual produk komoditas langsung kekonsumen secara sedikit demi sedikit atau satuan, pemilik took atau warung adalah pengecer. ${ }^{2}$

\section{c. Definisi decision support system}

Decision support system merupakan sistem informasi pada level manajemen dari suatu organisasi yang mengkombinasikan data dan mode analisis canggih atau peralatan data analisis untuk mendukung pengambilan yang mengkombinasikan data dan mode analisis canggih atau peralatan data analisis untuk mendukung pengambilan yang semi terstrukutur dan tidak terstruktur. (Hanif Al Fatta, 2007: h.13).

d. Tujuan Sistem Penunjang keputusan

1. Membantu manajer mengambil keputusan setengah terstruktur yang dihadapi oleh manajer level menegah

\footnotetext{
${ }^{1}$ https://id.wikipedia.org/wiki/Pasar

2 https://id.wikipedia.org/wiki/Pedagang
}

2. Membantu

atau

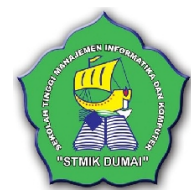

manajemen mengambil keputusan bukan menggantikannya.

3. c. Meningkatkan efektifitas pengambilan keputusan manajemen bukan untuk meningkatkan efisiensi. penggunaan SPK. (Jogiyanto.2009.h 328)

\section{e. Pengertian Metode SAW}

Menurut Pratomo Setiaji (2012), Metode Simple Additive Weighting (SAW) sering juga dikenal istilah metode penjumlahan terbobot. Konsep dasar metode SAW adalah mencari penjumlahan terbobot dari rating kinerja pada setiap alternatif pada semua atribut. Metode SAW membutuhkan proses normalisasi matriks keputusan (X) ke suatu skala yang dapat diperbandingkan dengan semua rating alternatif yang ada.

\section{f. Langkah Penyelesaian Metode Simple Additive Weighting (SAW) \\ Langkah - langkah Penyelesaian Metode} Simple Additive Weighting (SAW) sebagai berikut:

1. Menentukan kriteria-kriteria yang akan dijadikan acuan dalam pengambilan keputusan, yaitu $\mathrm{Ci}$.

2. Menentukan rating kecocokan setiap alternatif pada setiap kriteria.

3. Membuat matriks keputusan berdasarkan criteria (Ci), kemudian melakukan normalisasi matriks berdasarkan persamaan yang disesuaikan dengan jenis atribut (atribut keuntungan ataupun atribut biaya) sehingga diperoleh matriks ternormalisasi R.

4. Hasil akhir diperoleh dari proses perankingan yaitu penjumlahan dari perkalian matriks ternormalisasi $\mathrm{R}$ dengan vektor bobot sehingga diperoleh nilai terbesar yang dipilih sebagai alternative terbaik (Ai) sebagai solusi.

Rumus untuk melakukan normalisasi tersebut adalah:

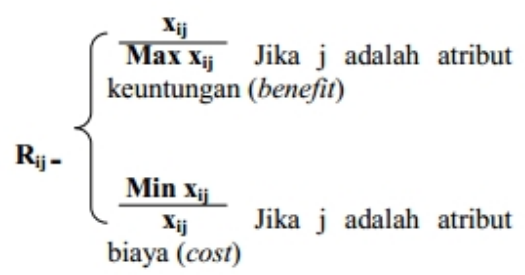

Dimana:

$\mathrm{r}_{\mathrm{ij}}=$ rating kinerja ternormalisasi

$\operatorname{Max}_{\mathrm{ij}}=$ nilai maksimum dari setiap baris dan kolom 
I N F O R M A I K A

Jurnal Informatika, Manajemen dan Komputer, Vol. 8 No. 2 , Desember 2016

elSSN : 2580-3042

pISSN : 1979-0694

$\operatorname{Min}_{\mathrm{ij}}=$ nilai minimum dari setiap baris dan kolom

$\mathrm{X}_{\mathrm{ij}} \quad=$ baris dan kolom dari matriks

Dengan $r_{i j}$ adalah rating kinerja ternormalisasi dari alternatif $A_{i}$ pada atribut $C_{j} ; i=1,2,, m$ dan $j=$ $1,2,,, n$.

Nilai preferensi untuk setiap alternatif $\left(\mathrm{V}_{\mathrm{i}}\right)$ diberikan sebagai:

$$
V_{i}=\sum_{j=1}^{n} w_{j} r_{i j}
$$

Dimana :

$\mathrm{V}_{\mathrm{i}}=$ Nilai akhir dari alternatif

$\mathrm{W}_{\mathrm{i}}=$ Bobot yang telah ditentukan

$\mathrm{r}_{\mathrm{ii}}=$ Normalisasi matriks

Nilai $\mathrm{V}_{\mathrm{i}}$ yang lebih besar mengindikasikan bahwa alternatif $\mathrm{A}_{\mathrm{i}}$ lebih terpilih.

\section{METODOLOGI PENELITIAN}

Dalam penulisan proposal skripsi ini metode yang digunakan adalah :

a. Tempat dan Waktu Penelitian

Penelitian ini dilakukan di Kantor Pelayanan kota Dumai, waktu yang diperlukan dalam penelitian ini membutuhkan beberapa bulan untuk penyelesaiannya terhitung dari bulan Mei s/d November 2015.

b. Jenis penelitian

1. Penelitian Lapangan (Field Research)

2. Penelitian Kepustakaan (Library

Research)

3. Penelitian Laboratorium (laboratory Research)

c. Teknik Analisa Data

Penelitian kualitatif diartikan sebagai salah satu prosedur penelitian yang menghasilkan data deskriptif. Metode deskriptif digunakan dalam usaha untuk mencari, mengumpulkan data, menyusun, menggunakan serta menafsirkan data yang sudah ada untuk menguraikan secara lengkap dan komperhensif. Ciri-ciri umum metode deskriptif adalah menggambarkan fakta-fakta tentang masalah yang diselidiki, Memusatkan perhatian terhadap masalah yang ada pada saat penelitian dilakukan atau masalah yang bersifat aktual.

\section{HASIL DAN PEMBAHASAN}

a. Aliran Sistem Informasi (ASI) yang Baru

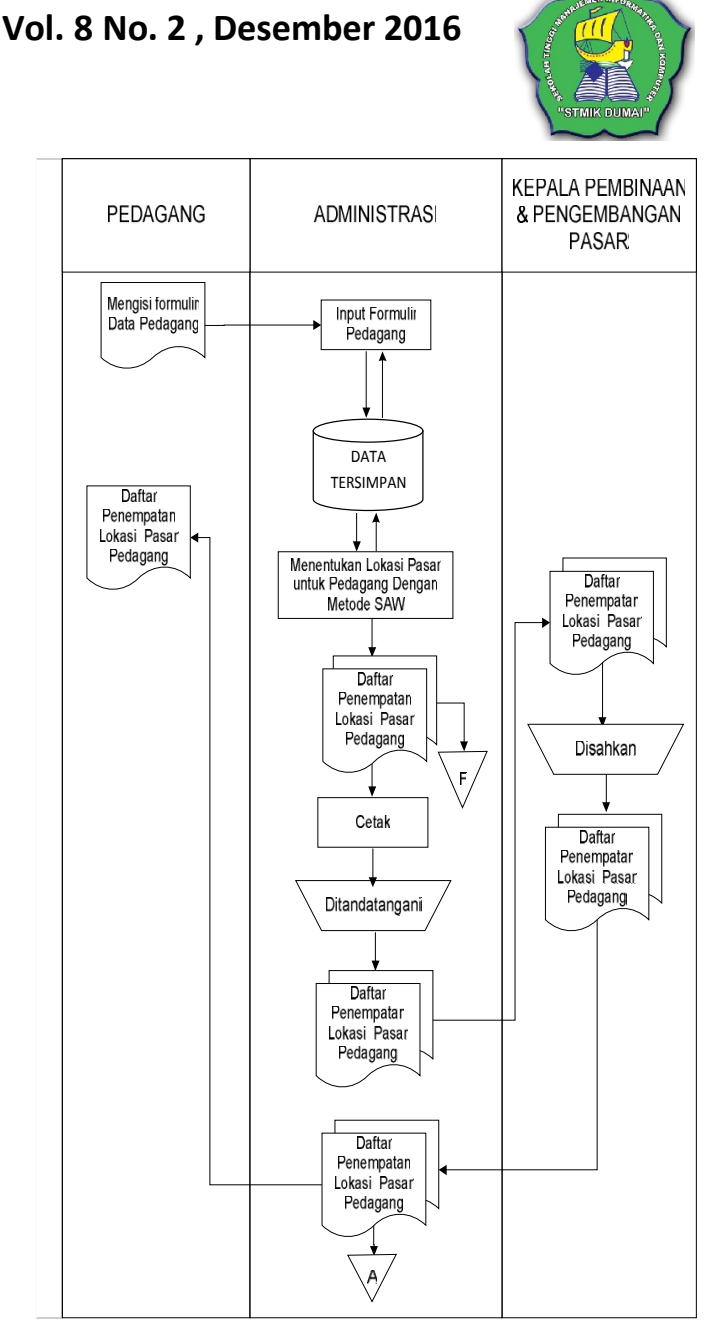

Gambar 1. ASI yang Baru

\section{b. Context Diagram}

Untuk menggambarkan hubungan sistem dengan entitas luarnya, dapat dilihat pada gambar Context Diagram dibawah ini :

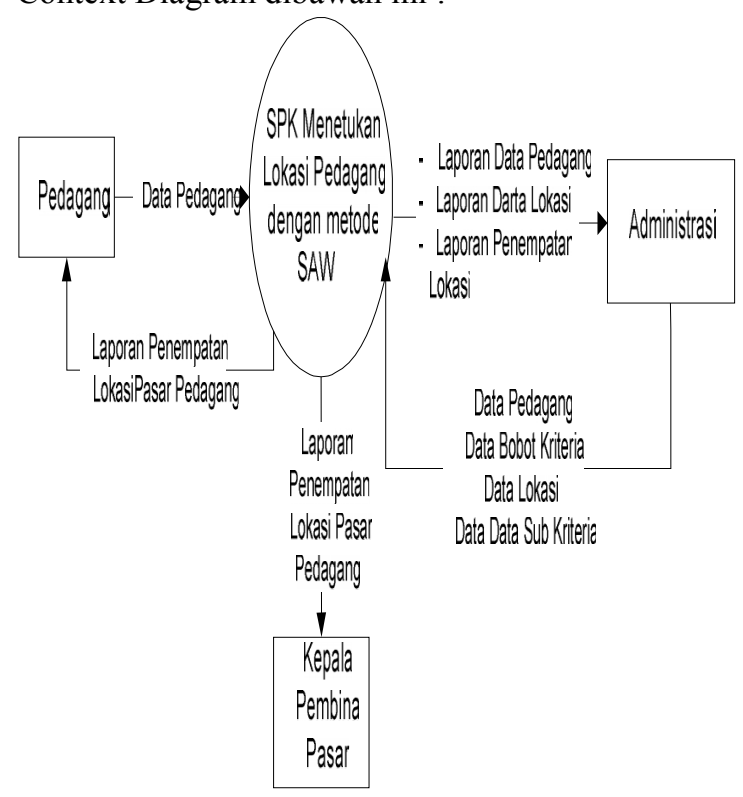

Gambar 2. Context Diagram 
I N F ORM I T I K

Jurnal Informatika, Manajemen dan Komputer, Vol. 8 No. 2 , Desember 2016

eISSN : 2580-3042

pISSN : 1979-0694

\section{c. Data Flow Diagram}

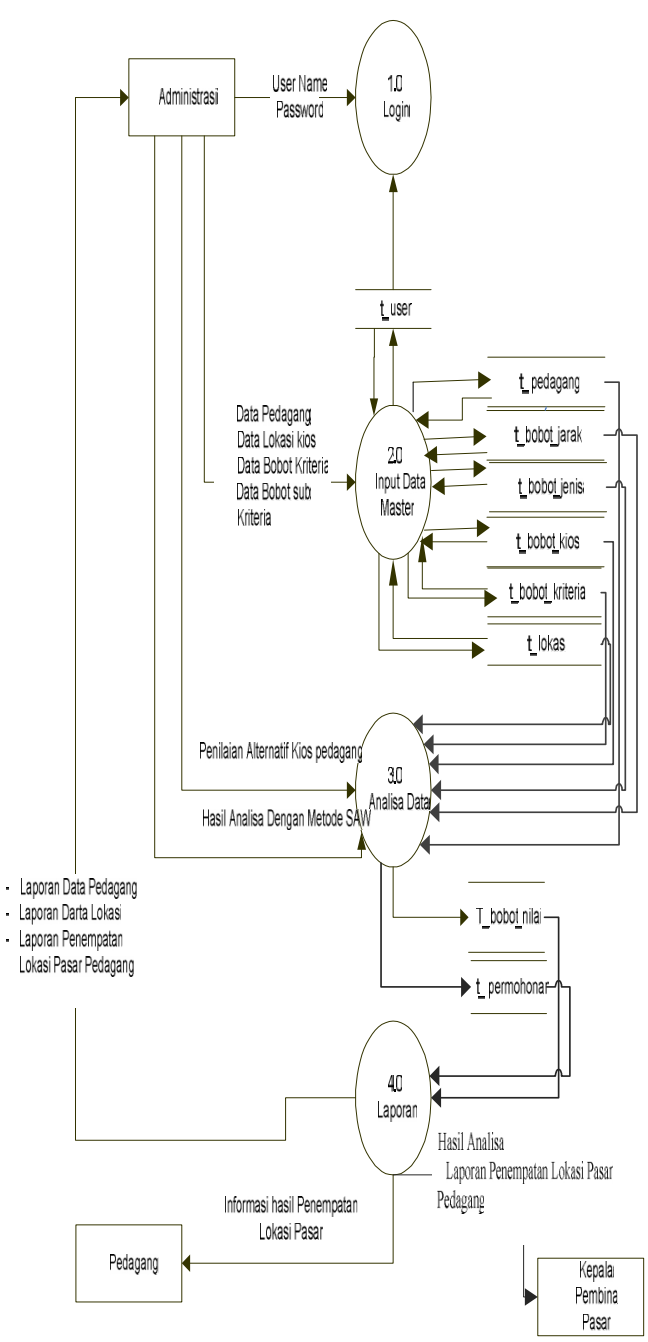

Gambar 3. Data Flow Diagram

\section{c. Analisa Metode SAW}

Tahapan penyelesaian metode SAW pada kasus menentukan lokasi pasar kota Dumai.

1. Menentukan criteria peniliaian dalam membuat keputusan $(\mathrm{Ci})$

$\mathrm{C} 1=$ Ukuran Kios (benefit)

$\mathrm{C} 2=$ Jarak Tempuh (benefit)

C3= Jenis Dagangan (cost)

2. Memberikan pembobotan untuk tiap criteria
$\mathrm{C} 1=25$
$\mathrm{C} 2=25$
$\mathrm{C} 3=50$
Total $=100$

3. Memberikan bobot nilai dari masing-masing alternative, maksimum dari pembobotan adalah 100
Tabel 1. Kriteria

\begin{tabular}{|l|c|c|c|}
\hline \multirow{2}{*}{\multicolumn{1}{c|}{ Alternatif }} & \multicolumn{3}{c|}{ Kriteria } \\
\cline { 2 - 4 } & C1 & C2 & C3 \\
\hline ARLINA & 50 & 80 & 45 \\
\hline JURMALIS & 75 & 60 & 30 \\
\hline SUPRAYIATO & 50 & 60 & 30 \\
\hline HERFENDI & 75 & 50 & 45 \\
\hline $\begin{array}{l}\text { ENDANG } \\
\text { PURWANTI }\end{array}$ & 75 & 60 & 65 \\
\hline
\end{tabular}

4. Hitung Normalisasi dari setiap alternative untuk faktor benefit dan cost,

Arlina

C1 (benefit) : $50 / 75=0,67$

C2 (benefit) : $80 / 80=1$

$\mathrm{C} 3$ (Cost) : $30 / 45=0,67$

$\cdots$

Tabel 2. Hasil setelah dinormalisasi keseluruhan alternatif

\begin{tabular}{|c|c|c|c|}
\hline \multirow{2}{*}{ Alternatif } & \multicolumn{3}{|c|}{ Kriteria } \\
\cline { 2 - 4 } & C1 & C2 & C3 \\
\hline ARLINA & 0,67 & 1 & 0,67 \\
\hline JURMALIS & 1 & 0,75 & 1 \\
\hline SUPRAYIATO & 0,67 & 0,75 & 1 \\
\hline HERFENDI & 1 & 0,625 & 0,67 \\
\hline ENDANG & 1 & 0,75 & 0,46 \\
PURWANTI & & & \\
\hline
\end{tabular}

5. Langkah terakhir masing-masing bobot vector yang telah dinormalisasi dikalikan dengan bobot criteria

$\underline{\text { Arlina }}$

$\mathrm{C} 1: 0,67 * 25=16,67$

$\mathrm{C} 2: 1 * 25=25$

$\mathrm{C} 3: 1,5 * 50=33,33$

Total $=16,67+25+33,33=75$

Tabel 3. Hasil setelah keseluruhan alternative dikalikan dengan nilai bobo kriteria

\begin{tabular}{|c|c|c|c|c|}
\hline \multirow{2}{*}{ Alternatif } & \multicolumn{3}{|c|}{ Kriteria } & \multirow{2}{*}{$\begin{array}{c}\text { Tot } \\
\text { al }\end{array}$} \\
\hline & C1 & $\mathrm{C} 2$ & C3 & \\
\hline ARLINA & $\begin{array}{c}16,6 \\
7\end{array}$ & 25 & 33,3 & 75 \\
\hline JURMALIS & 25 & 18,75 & 50 & $\begin{array}{c}93,7 \\
5\end{array}$ \\
\hline $\begin{array}{c}\text { SUPRAYIA } \\
\text { TO }\end{array}$ & $\begin{array}{c}16,6 \\
7\end{array}$ & 18,75 & 50 & $\begin{array}{c}85,4 \\
2\end{array}$ \\
\hline HERFENDI & 25 & $\begin{array}{c}15,62 \\
5\end{array}$ & $\begin{array}{c}33,3 \\
3\end{array}$ & $\begin{array}{c}73,9 \\
5\end{array}$ \\
\hline $\begin{array}{c}\text { ENDANG } \\
\text { PURWANTI }\end{array}$ & 25 & 18,75 & $\begin{array}{c}23,0 \\
7\end{array}$ & $\begin{array}{c}66,8 \\
2\end{array}$ \\
\hline
\end{tabular}

Ket: Setelah dilakukan penjumlahan ketiga krietria terhadap 5 alternatif maka terdapat 1 alternatif pilihan yaitu "Jurmalis" dengan total 
I N F O R M A I K A

Jurnal Informatika, Manajemen dan Komputer, Vol. 8 No. 2 , Desember 2016

elSSN : 2580-3042

pISSN : 1979-0694

nilai: 93,75. Karena memiliki total nilai tertinggi dari alternative yang lain.

\section{d. Implementasi Sistem \\ a. Form Login}

Jalankan program aplikasi dengan cara mengklik icon program aplikasi. Setelah itu maka akan muncul form Log In. masukkan Hak Akses dan Password. Jika setelah diisi dengan benar, maka menu utama aplikasi akan tampil.

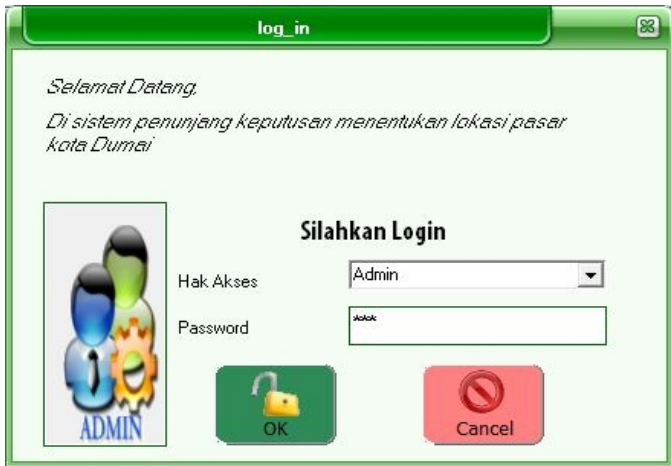

Gambar 4. Form Login

\section{b. Form Menu Utama}

Setelah mengisi form login dengan benar, maka kita akan masuk ke menu utama aplikasi:

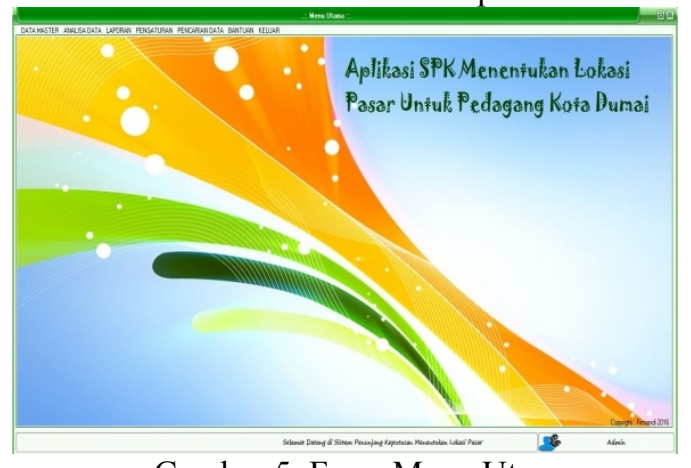

Gambar 5. Form Menu Utama

\section{c. Data Master}

\section{Form Pedagang}

Pada Menu Utama, klik Data Master kemudian pilih Data Pedagang, maka akan tampil form seperti gambar dibawah ini :

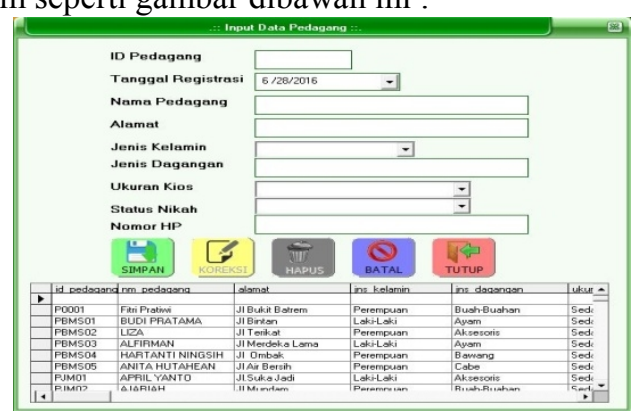

Gambar 6. Form Pedagang

\section{Form Bobot Kriteria}

Pada Menu Utama, klik Data Master kemudian pilih input data bobot kriteria maka akan tampil form seperti gambar dibawah ini :

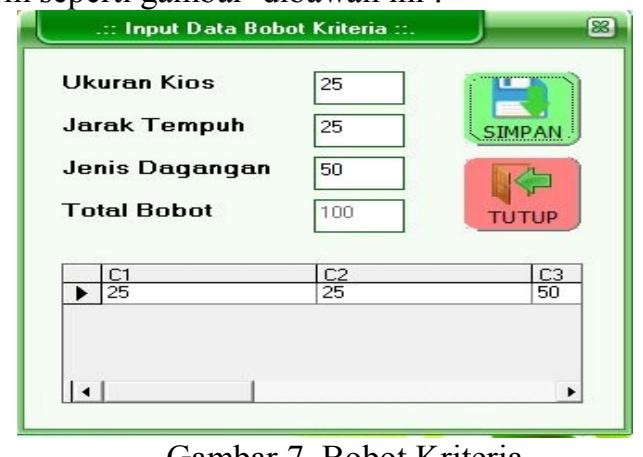

\section{Form Input Lokasi}

Pada Menu Utama, klik Data Master kemudian pilih input data Lokasi maka akan tampil form seperti gambar dibawah ini

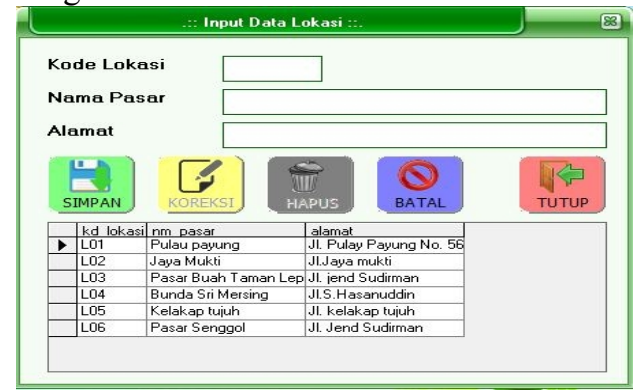

Gambar 8. Input Lokasi

\section{d. Analisa Data}

\section{Form penilaian}

Pada Menu Utama, klik Analsia Data kemudian pilih penilaian alternatif kios pedagang maka akan tampil form seperti gambar dibawah ini :

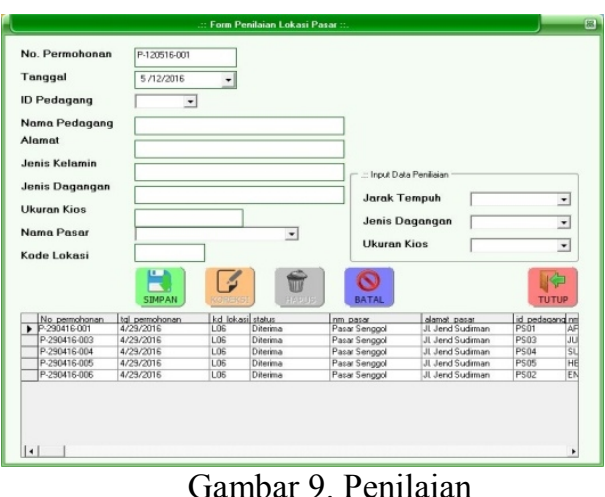

\section{Form Analisa SAW}

Pada Menu Utama, klik Analsia Data kemudian pilih "Hasil analisa dengan metode saw" maka akan tampil form seperti gambar dibawah ini 
I N F ORM A I I A

Jurnal Informatika, Manajemen dan Komputer, Vol. 8 No. 2 , Desember 2016

eISSN : 2580-3042

pISSN : 1979-0694

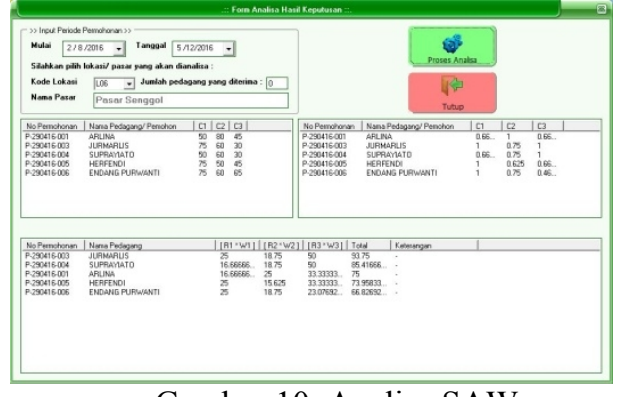

Gambar 10. Analisa SAW

\section{KESIMPULAN}

Perkembangan ilmu pengetahuan dan teknologi saat ini sangat pesat, sehinga menuntut kita untuk terus mengikuti perkembangan tersebut. Teknologi khususnya komputer sangat membantu pekerjaan manusia dalam mengolah data, memberikan informasi yang dibutuhkan secara cepat dan akurat sesuai kebutuhan.

Berdasarkan hasil penelitian yang telah dilakukan pada kantor pelayanan pasar kota Dumai, maka dapat ditarik kesimpulan bahwa:

1. Dengan memanfaatkan aplikasi Sistem Penunjang Keputusan (SPK) untuk menentukan lokasi pasar bagi pedagang kota Dumai, maka Kantor Pelayanan Pasar Kota Dumai dapat menentukan lokasi pasar bagi siapa saja calon pedagang yang telah memenuhi kriteria dan bobot yang telah ditetapkan mengunakan metode SAW.

2. Dengan menggunakan bahasa pemograman Visual Basic 6 dan database MySql versi 5.0.51b pada aplikasi yang dibuat maka dapat membangun suatu aplikasi yang dinamis dan mudah digunakan bagi kantor pelayanan pasar kota Dumai, serta tidak akan ada resiko redudansi data karena jika ada field kunci data yang sama maka data tidak bisa dismpan.

3. Memudahkan admin dalam melakukan pembuatan laporan penempatan pedagang disalah satu pasar dikota Dumai berdasarkan bobot dan kriteria yang telah ditentukan mengunakan metode SAW.

\section{REFERENSI}

Budi Raharjo. 2011. Belajar Otodidak Membuat Database Menggunakan MySQL. Informatika: Bandung.

Fathansyah. 2012. Basis Data. Informatka: Bandung.

Hanif Al Fatta. 2007. Analisis dan Perancangan Sistem Informasi. Andi: Yogyakarta.

Indrajani. 2011. Perancangan Basis Data Dalam All in 1. PT Elex Media Komputindo :

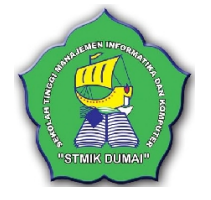

Jakarta.

Jogiyanto HM. 2009. Sistem Teknologi Informasi. Andi: Yogyakarta..

2009. Analisis dan Desain Sistem Informasi. Andi: Yogyakarta.

Jubilee Enterprise. 2014. MySQL untuk Pemula. PT Elex Media Komputindo : Jakarta.

Mardiani, Kurniawan, Rahmansyah. 2011. Aplikasi Penjualan dengan Program java Netbenas, Xammp, dan iReport. PT Elex Media Komputindo : Jakarta.

Muhammad Sadeli. 2012. Apliksi Sms dengan Visual basic 6.0 dan Visual basic 2010. Maxicom : Palembang

Riyanto. Membuat Sediri Aplikasi Web Store dengan PHP, JQuery dan Microsoft SQLServer. Gava Media : Yogyakarta.

Suarga. 2012. Agoritma dan Pemograman. Andi: Yogyakarta.

Tan Amelia. 2008. Membangun Aplikasi Database Menggunakan ADO.NET 2.0. Cerdas Pustaka : Jakarta. 